\title{
SDR: UM NOVO MÉTODO PARA AVALIAR A VULNERABILIDADE NATURAL À CONTAMINAÇÃO DE AQUÍFEROS LIVRES GRANULARES
}

\author{
SDR: A NEW METHOD TO ASSESS THE NATURAL VULNERABILITY TO CONTAMINATION \\ OF GRANULAR UNCONFINED AQUIFERS
}

\section{Richard Fonseca FRANCISCO ${ }^{1}$, Antonio Celso de Oliveira BRAGA ${ }^{1}$, José Luiz ALBUQUERQUE FILHO ${ }^{2}$}

${ }^{1}$ Instituto de Geociências e Ciências Exatas, Universidade Estadual Paulista, UNESP, Avenida 24-A, no 1515, Bela Vista, Rio Claro (SP), CEP 13506-900. Emails: richardfon1@ @otmail.com; acobraga@rc.unesp.br

${ }^{2}$ Instituto de Pesquisas Tecnológicas do Estado de São Paulo - IPT, Avenida Professor Almeida Prado 532, Cidade Universitária, Butantã, São Paulo (SP), CEP: 05508-901. Email: albuzelu@ipt.br

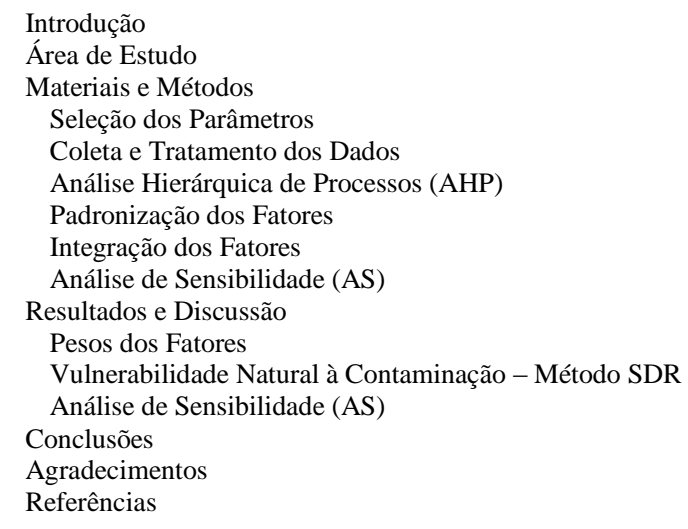

RESUMO - Diante do crescente número de áreas contaminadas, que comprometem a qualidade dos aquíferos e constituem riscos à saúde humana, torna-se imprescindível o estabelecimento de instrumentos para o planejamento e gestão do uso do solo, visando à proteção das águas subterrâneas. Por essa razão, o objetivo deste trabalho foi desenvolver e aplicar, experimentalmente, um novo método para avaliar a vulnerabilidade natural à contaminação de aquíferos livres granulares. Para tanto, foram selecionados, ponderados e integrados os fatores condutância longitudinal unitária $\left(\mathrm{S}_{\mathrm{i}}\right)$, declividade $(\mathrm{D})$ e recarga $(\mathrm{R})$ - método SDR, com suporte da Avaliação Multicritério (AMC) e técnicas de geoprocessamento operadas em ambiente SIG. A área teste escolhida para aplicar este novo modelo foi o Aquífero Rio Claro, situado no município de Rio Claro/SP. Quanto ao resultado, toda a área de estudo apresentou alta vulnerabilidade natural, o que é compatível com aqueles reportados em trabalhos anteriores. Devido à robustez do resultado, à praticidade na utilização e ao número reduzido de parâmetros requeridos, o método SDR representa uma nova alternativa àqueles considerados tradicionais, podendo desempenhar um papel importante na proteção de aquíferos livres granulares.

Palavras-chave: Aquífero Rio Claro, Vulnerabilidade, Método SDR, Condutância Longitudinal Unitária, Avaliação Multicritério.

\begin{abstract}
In view of increase in the number of contaminated areas, which compromise the groundwater quality and constitute risks to human health, it is essential to establish instruments for land use planning and management, aiming at the groundwater protection. Thus, the aim of this work was to develop and apply, experimentally, a new method to assess the natural vulnerability to contamination of granular unconfined aquifers. For this purpose, longitudinal unit conductance $\left(\mathrm{S}_{\mathrm{i}}\right)$, slope $(\mathrm{D})$ and recharge $(\mathrm{R})$ factors were selected, weighted and integrated - SDR method, with support of Multicriteria Evaluation (MCE) and geoprocessing techniques operated in GIS environment. Located in the Rio Claro municipality, São Paulo State, Brazil, the Rio Claro Aquifer was chosen to apply this new evaluation method. With respect to result, the entire study area presented high natural vulnerability, which is compatible with those reported in previous studies. Due to robust result, the practical use and the reduced number of required parameters, the SDR method represents a new alternative to traditional methods and may play an important role to granular unconfined aquifers protection. Keywords: Rio Claro Aquifer, Vulnerability, SDR Method, Longitudinal Unit Conductance, Multicriteria Evaluation.
\end{abstract}

\section{INTRODUÇÃO}

A importância da realização de estudos de vulnerabilidade natural à contaminação é inquestionável, visto que a remediação de uma área tende sempre a ser difícil e impraticável em diversas situações, sob o âmbito financeiro, técnico e operacional. Sem dúvida alguma, estudos sistemáticos desta natureza representam uma ação preventiva extremamente eficaz, pois seus resultados permitem priorizar e direcionar esforços tecnológicos e financeiros a regiões mais críticas, subsidiando o Poder Público na tomada de decisões referentes à gestão do uso e proteção dos aquíferos.

Nas últimas décadas, foram desenvolvidos uma série de métodos para avaliar a vulnerabilidade natural à contaminação de 
aquíferos, tais como: DRASTIC (Aller et al., 1987); GOD (Foster \& Hirata, 1988); AVI (Van Stempvoort et al., 1992) e SINTACS (Civita \& De Maio, 1997).

Todavia, a disponibilidade dos parâmetros requeridos pode configurar um entrave à aplicação destes modelos de avaliação, principalmente em países como o Brasil, onde ainda há carência de dados geológicos e hidrogeológicos, em diversas regiões do país. Por isso, torna-se necessária a adaptação desses modelos, baseada na supressão ou na inserção de parâmetros disponíveis, propondo novos métodos de avaliação.

Recentemente, alguns trabalhos demonstraram resultados bastante favoráveis à utilização do parâmetro de Dar Zarrouk denominado condutância longitudinal unitária $\left(S_{i}\right)$ na estimativa do "grau de proteção" ou "vulnerabilidade natural" de aquíferos à contaminação (Braga \& Francisco, 2014; Sendròs et al., 2014; Akpan et al., 2015; Ndatuwong \& Yadav, 2015; Niaz et al., 2016; Mosuro et al., 2016; Gemail et al., 2017).

A condutância longitudinal unitária representa a razão entre as espessuras e resistividades elétricas das camadas sobrejacentes ao aquífero de interesse, podendo ser adquirida a custos e prazos reduzidos, se comparada a perfurações e campanhas de amostragem de poços tubulares.

A partir do cálculo da condutância longitudinal total (S) da zona não saturada, tem-se que, quanto maior o valor de $\mathrm{S}$, maior será o grau de proteção do aquífero, pois: (1) quanto maior a espessura da zona insaturada, maior o tempo de percolação do contaminante (maior filtro); e (2) quanto menor sua resistividade, mais argiloso e menos permeável é o material (Braga, 2016).

Contudo, ainda não existe uma abordagem alicerçada na análise integrada entre a condutância longitudinal unitária e demais fatores que interferem na estimativa de vulnerabilidade natural, resultando na lacuna de conhecimento sobre a estruturação de um novo método para uma avaliação mais robusta do problema e obtenção de resultados talvez mais práticos.

Diante do exposto, o objetivo deste trabalho foi desenvolver e aplicar, experimentalmente, um novo método para avaliar a vulnerabilidade natural à contaminação de aquíferos livres granulares. Para tanto, foram selecionados, ponderados e integrados os fatores condutância longitudinal unitária $\left(S_{i}\right)$, declividade (D) e recarga $(\mathrm{R})$ - método SDR, com suporte da Avaliação Multicritério (AMC) e técnicas de geoprocessamento operadas em ambiente SIG.

\section{ÁREA DE ESTUDO}

A área de estudo representa um fragmento da Formação Rio Claro, com superfície total de aproximadamente $95 \mathrm{~km}^{2}$. Localiza-se no município de Rio Claro, no centro-leste do Estado de São Paulo, entre as coordenadas UTM 232692 243646 W e 7512521 - 7535805 S (Figura 1).

Quanto ao contexto geológico (Figura 2), a área de estudo situa-se na porção nordeste da Bacia Sedimentar do Paraná, onde ocorrem rochas sedimentares e vulcânicas das eras: Paleozoica (Subgrupo Itararé, formações Tatuí, Irati e Corumbataí), Mesozoica (Formação Pirambóia e Intrusivas Básicas) e Cenozoica (Formação Rio Claro e Coberturas Indiferenciadas) (IG, 1986).

A Formação Rio Claro apresenta como características marcantes: fraca litificação e profunda alteração pedogenética, espesso solo arenoso e domínio de litotipos arenosos, esbranquiçados, amarelados a avermelhados, variando de areia fina a grossa, com intercalação de camadas de conglomerados e de sedimentos argilosos. A espessura máxima é da ordem de 40 metros, predominando valores entre 25 metros e 30 metros (Zaine, 1994). No que se refere às relações de contato, a Formação Rio Claro assenta-se em discordância sobre os argilitos e siltitos da Formação Corumbataí, no município de Rio Claro/SP (Melo, 1995).

O Aquífero Rio Claro é uma unidade hidrogeológica constituída por sedimentos pouco consolidados da Formação Rio Claro, apresentando extensão local, superfície descontínua e livre, cuja recarga ocorre por toda a sua extensão, diretamente através da infiltração das precipitações. A rede hidrográfica local atua como zonas de descarga do Aquífero Rio Claro, as quais, geralmente, situam-se próximas ao contato do aquífero com o aquitardo subjacente, constituído pela Formação Corumbataí (DAEE, 1981; Oliva, 2006). Chang et al. (2005) determinaram valores de condutividade hidráulica para a zona saturada situados entre $10^{-2} \mathrm{~cm} / \mathrm{s}$ e $10^{-4} \mathrm{~cm} / \mathrm{s}$, atribuindo à Formação Rio Claro excelente permo-porosidade. Para o Aquífero Rio Claro, a razão anual entre a recarga e a precipitação foi estimada em $13 \%$ (Chang \& Nogueira, 2015). 


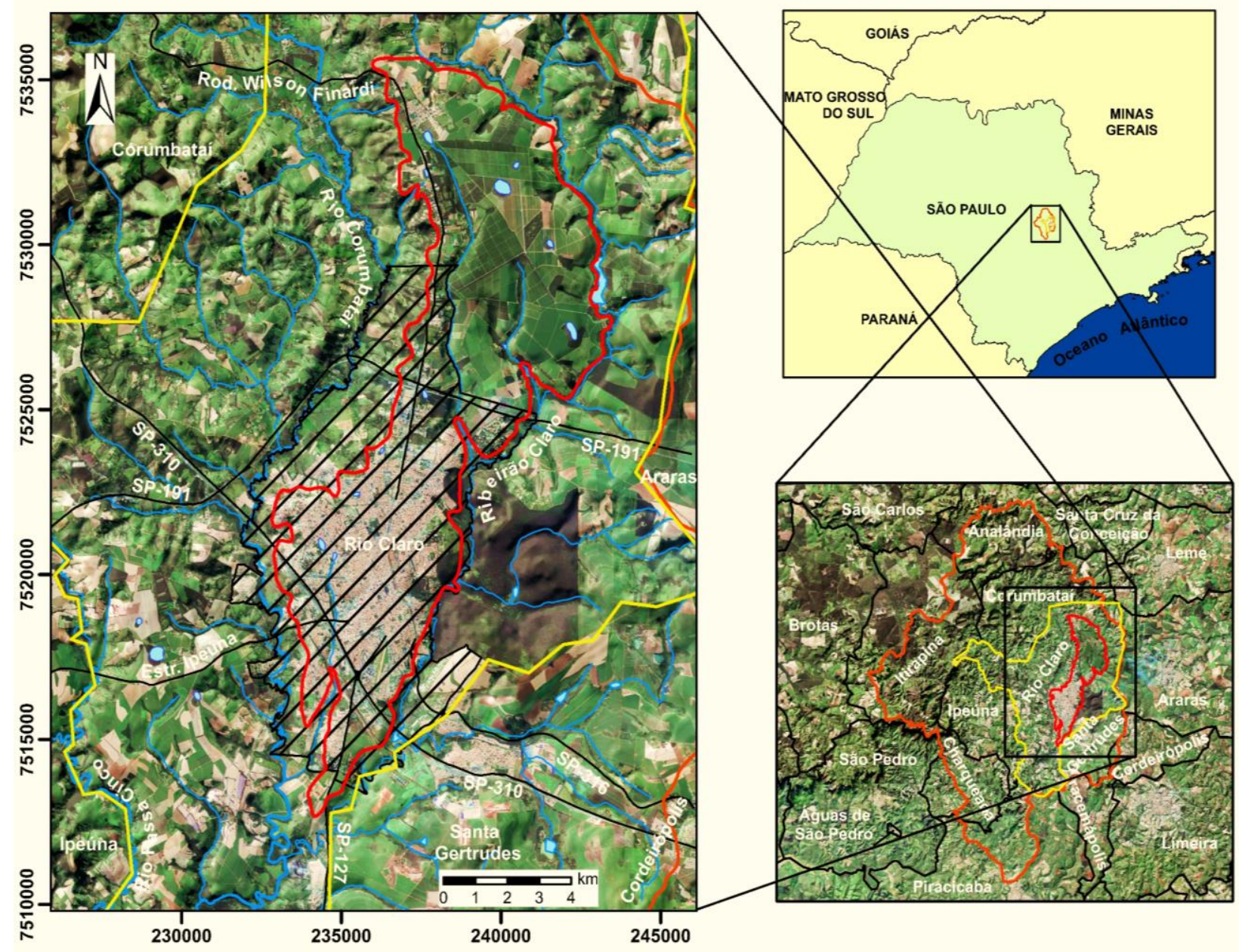

\begin{tabular}{ll} 
Legenda & Bacia Hidrográfica do Rio Corumbataí \\
Área de Estudo (Fragmento & Lagos, Lagoas e Represas \\
da Formação Rio Claro) & Rede Hidrográfica Principal \\
Municipio de Rio Claro/SP & Rodovias Estaduais \\
\hline
\end{tabular}

Base Cartográfica: IBGE (2007)

Relevo Sombreado: Imagem SRTM/

Projeto TOPODATA (2011)

Composição 4R3G2B: Landsat 8 OLI,

órbita/pontos 220/75 e 76 (USGS, 2015)

Projeção: UTM/SIRGAS 2000

Fuso: 235

Meridiano Central: $45^{\circ} \mathrm{W}$

Figura 1. Mapa de localização da área de estudo.

\section{MATERIAIS E MÉTODOS}

\section{Seleção dos Parâmetros}

Para definir os parâmetros a serem utilizados no novo modelo de avaliação proposto (método SDR) e, posteriormente, calcular os pesos de influência desses fatores para a avaliação de vulnerabilidade natural, empregou-se a Técnica Participatória (Eastman, 2011). Ao todo, foram consultados 7 especialistas nas áreas de hidrogeologia, geofísica aplicada e recursos hídricos, com suporte de uma revisão bibliográfica aprofundada acerca do tema estudado. Conforme os especialistas, para analisar a vulnerabilidade natural de forma integrada, são relevantes para o estudo os seguintes fatores:

I. CONDUTÂNCIA LONGITUDINAL UNITÁRIA $\left(S_{i}\right)$ : contém, mesmo que de modo implícito, dois parâmetros fundamentais à estimativa de vulnerabilidade natural, são eles: (i) a profundidade do nível da água subterrânea (N.A.); e (ii) as características dos materiais da zona insaturada, as quais são correlacionáveis aos valores de resistividade elétrica, após o processamento e análise dos dados de resistividade aparente;

II. DECLIVIDADE $(D)$ : exerce controle sobre o tempo de permanência da água na superfície do solo e, consequentemente, sobre a recarga. Além disso, a declividade influencia o desenvolvimento de perfis de solo, que podem interferir na atenuação de contaminantes ao longo da zona não saturada;

III. RECARGA $(R)$ : está relacionada à quantidade de águas pluviais que efetivamente conseguem 
atingir o aquífero, podendo transportar consigo os poluentes. Ademais, valores elevados de recarga de origem natural ou artificial podem atenuar os efeitos dos poluentes devido ao processo de diluição, fator que não foi considerado no âmbito do método SDR.

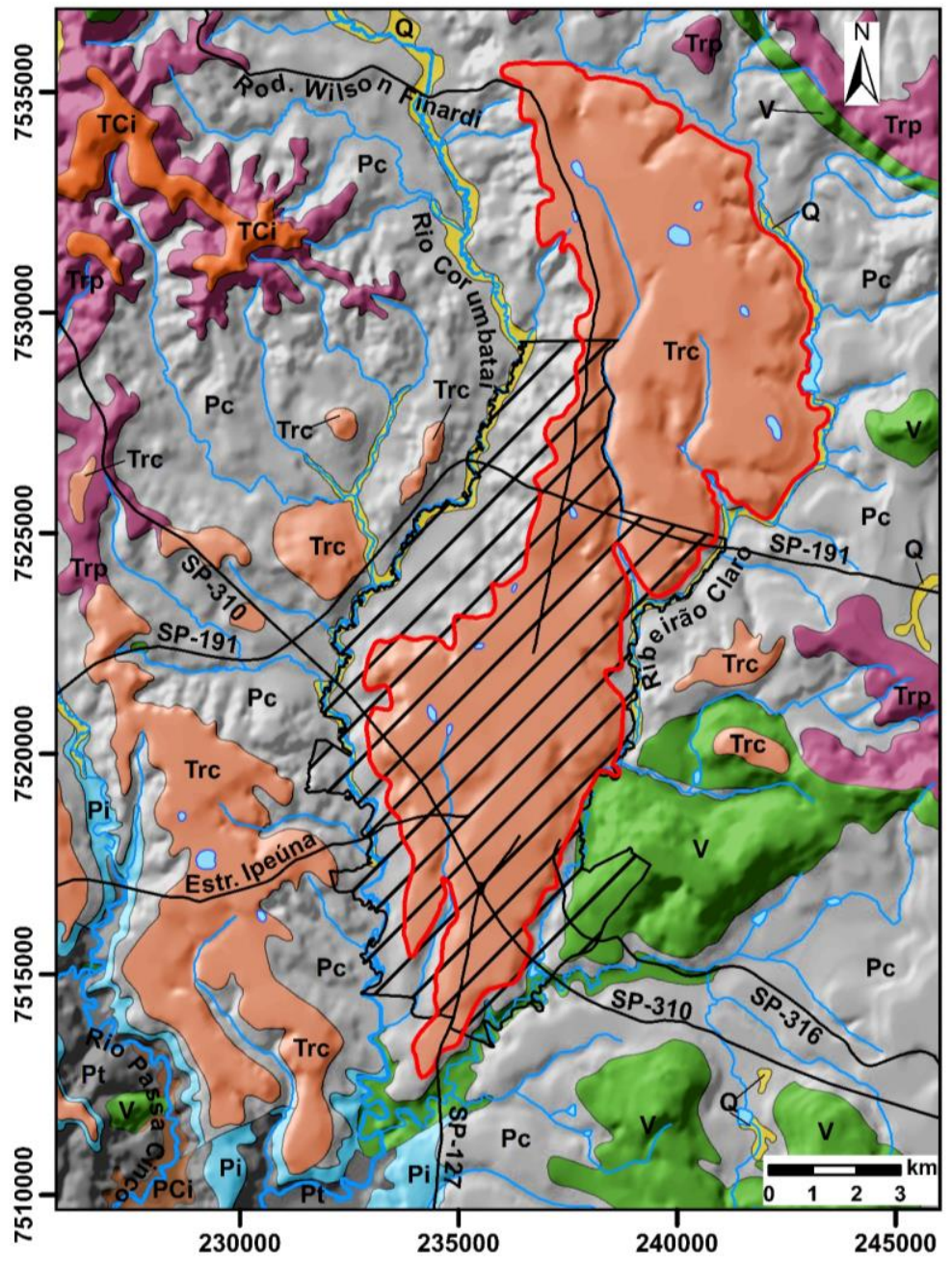

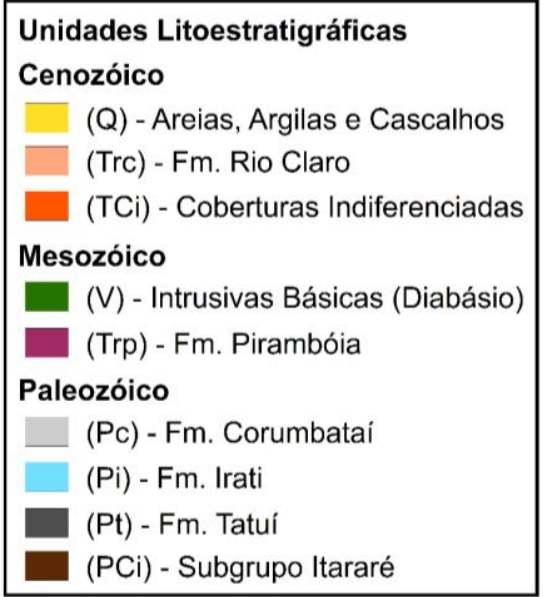

Legenda

Área de Estudo

Perímetro Urbano (Lei n 3806/2007)

Lagos, Lagoas e Represas

Rede Hidrográfica Principal

Rodovias Estaduais

Unidades Litoestratigráficas e Base Cartográfica: IG (1986)

Relevo Sombreado: Imagem SRTM INPE (2011)

Escala Original: 1:50.000

Projeção: UTM/SIRGAS 2000

Fuso: $23 \mathrm{~S}$

Meridiano Central: $45^{\circ} \mathrm{W}$

Figura 2. Contexto geológico da área de estudo. Fonte: Adaptado de IG (1986).

\section{Coleta e Tratamento dos Dados}

Os valores de condutância longitudinal unitária foram obtidos por meio da aplicação do método da eletrorresistividade e da técnica da Sondagem Elétrica Vertical (SEV) - arranjo Schlumberger. Assim, foram empregadas 121 SEVs realizadas por Oliva (2002, 2006), apresentadas na Figura 3.

Para utilizar a resistividade da zona não saturada ( $\left.\rho_{\text {insat }}\right)$ no cálculo de sua condutância longitudinal unitária, deve-se proceder a um ajuste, pois esta porção do solo apresenta valores de resistividade atípicos e com grandes variações, não refletindo, de um modo geral, a litologia local.

Por isso, foi utilizada a Equação 1 desenvolvida por Braga (2016), com base em Orellana (1972) e na Lei de Archie (1942). Em linhas gerais, as diferenças entre a resistividade ajustada para a zona insaturada $\left(\rho_{\mathrm{aj}}\right)$ e a resistividade da primeira camada da zona saturada $\left(\rho_{\text {sat }}\right)$ são ínfimas.

$\rho_{\mathbf{a j}}=\left[0,54\left(\frac{\rho_{\text {sat }}}{\rho_{\text {insat }}}\right)^{-2,25}\left(\frac{\rho_{\text {insat }}}{\rho_{\text {sat }}}\right)^{-2}\right] \rho_{\text {sat }}$

Considerando cada camada i componente da zona não saturada, com resistividade $\rho_{\mathrm{i}}(\Omega . \mathrm{m})$ e espessura $\mathrm{E}_{\mathrm{i}}(\mathrm{m})$, a condutância longitudinal unitária $\left(S_{i}\right)$ foi calculada através da Equação 2, cujas dimensões são expressas em siemens ou $\left(\Omega^{-1}\right)$.

O conjunto das $n$ camadas da seção geoelétrica resulta na condutância longitudinal total $(S)$ da zona não saturada, segundo demonstra a Equação 3 (Maillet, 1947; Henriet, 1975).

$$
\mathrm{S}_{\mathrm{i}}=\frac{\mathrm{E}_{\mathrm{i}}}{\rho_{\mathrm{i}}} \quad \text { (2) } \quad \mathrm{S}=\sum_{\mathrm{i}-1}^{\mathrm{n}} \frac{\mathrm{E}_{\mathrm{i}}}{\rho_{\mathrm{i}}}
$$




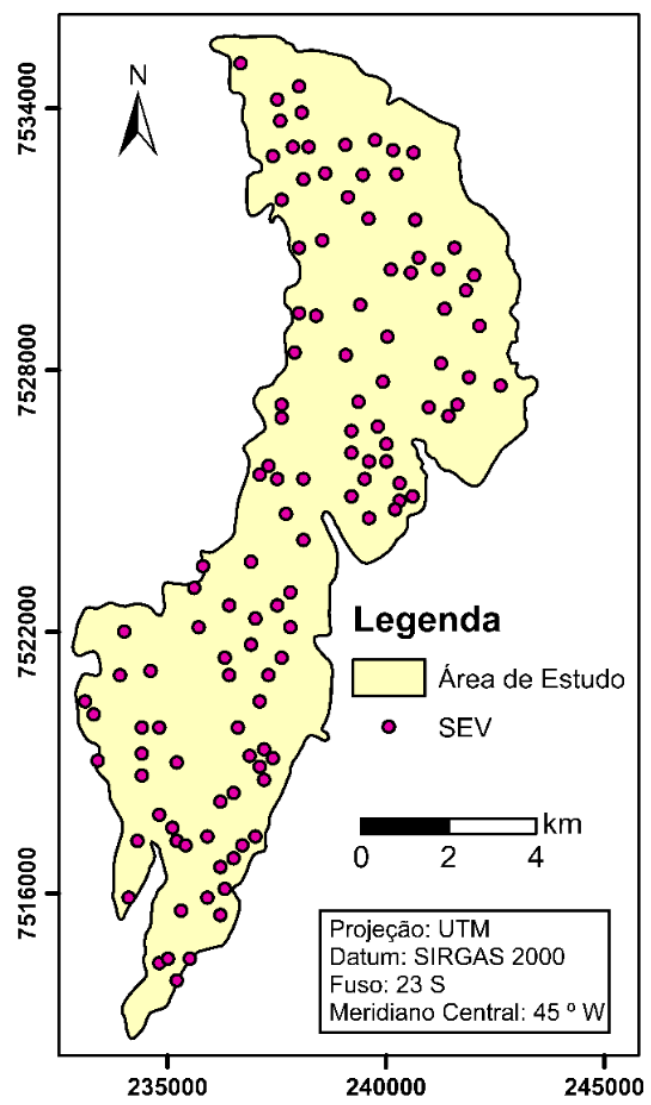

Figura 3. Localização das SEVs. Fonte: Adaptado de Oliva (2002, 2006).

Para a geração dos dados topográficos, foram utilizados pontos cotados, curvas de nível e rede hidrográfica da área urbana assentada sobre a Formação Rio Claro, na escala 1:10.000, formato shapefile (CEAPLA, 2011). Para o restante da área de estudo, a declividade foi obtida a partir da vetorização de dados altimétricos matriciais, contidos em cartas topográficas na escala 1:10.000 (IGC, 1979). No que se refere à recarga anual, foram utilizados os valores estimados por Gonçalves (2016), através de simulação numérica de fluxo do Aquífero Rio Claro, em regime estacionário, considerando o período de avaliação compreendido entre 2002 e 2014.

\section{Análise Hierárquica de Processos (AHP)}

No contexto da Avaliação Multicritério (AMC), foi empregada a Análise Hierárquica de Processos (AHP) para definir a importância relativa ou pesos de fator, para cada parâmetro considerado no método SDR. Desenvolvida por Saaty (1980, 2008), a AHP propõe a construção de uma matriz de comparação pareada entre os fatores, com base numa escala contínua de nove pontos (Tabela 1). A matriz gerada é simétrica e, portanto, somente a metade triangular superior necessita ser preenchida.

As células remanes-centes são recíprocas daquelas já preenchidas.

Tabela 1 - Escala fundamental de Saaty.

\begin{tabular}{c|c|l}
\hline $\begin{array}{c}\text { Expressão } \\
\text { Numérica }\end{array}$ & $\begin{array}{c}\text { Importância } \\
\text { Comparativa }\end{array}$ & \multicolumn{1}{c}{ Justificativa } \\
\hline 1 & Igualmente & Os dois critérios contribuem igualmente para o objetivo. \\
\hline 3 & Moderadamente & Importância moderada de um critério em relação ao outro. \\
\hline 5 & Fortemente & $\begin{array}{l}\text { Um critério é fortemente mais importante do que outro, } \\
\text { considerando o objetivo do trabalho. }\end{array}$ \\
\hline 7 & Muito Fortemente & Um critério é favorecido muito fortemente sobre o outro. \\
\hline $2,4,6$ e 8 & $\begin{array}{l}\text { Valores intermediários entre } \\
\text { escalas de valor adjacentes. }\end{array}$ & A importância de um critério sobre outro é da mais alta ordem. \\
\hline
\end{tabular}

Fonte: Adaptado de Saaty (2008) 
A consistência dos julgamentos paritários é avaliada por sua Razão de Consistência (RC), que representa a probabilidade de que os valores da matriz tenham sido gerados ao acaso ou randomicamente. Segundo Saaty (1980), os valores de RC devem estar sempre abaixo de 0,10, caso contrário, as comparações par a par devem ser reanalisadas. Para que fosse obtido apenas um conjunto de pesos de fator que sintetizasse a decisão do grupo de especialistas, foi utilizada a Agregação de Prioridades Individuais (API) (Forman \& Peniwati, 1998). Na API, cada indivíduo efetua seus julgamentos separadamente. Em seguida, calcula-se a média geométrica entre os pesos de fator gerados individualmente na AHP, obtendo-se, assim, os pesos finais que refletem a avaliação integrada do grupo.

\section{Padronização dos Fatores}

Devido às diferentes unidades de medida dos fatores, foi necessário colocá-los numa escala comum de comparação, entre 0 e 1 . Para padronizar o fator $\mathrm{R}$, foi utilizada uma função linear de pertinência fuzzy crescente, visto que a vulnerabilidade aumenta com o incremento dos escores (Equação 4). Aplicou-se uma função linear de pertinência fuzzy decrescente aos parâmetros Si e $\mathrm{D}$, pois quanto maior o escore, menor será a vulnerabilidade natural do aquífero (Equação 5):

$$
\begin{aligned}
& X_{i}=\frac{\left(R_{i}-R_{\text {mín. }}\right)}{\left(R_{\text {máx. }}-R_{\text {mín. }}\right)} \\
& X_{i}=\frac{\left(R_{\text {máx. }}-R_{i}\right)}{\left(R_{\text {máx. }}-R_{\text {mín. }}\right)}
\end{aligned}
$$

onde: $\mathrm{X}_{\mathrm{i}}=$ escore padronizado; $\mathrm{R}_{\mathrm{i}}=$ escore bruto, $\mathrm{R}_{\text {máx. }}$ e $\mathrm{R}_{\text {mín. }}=$ pontos de controle a e $\mathrm{b}$ (Figura 4 ), que foram retirados do método DRASTIC (Aller et al., 1987) e de Braga (2016).

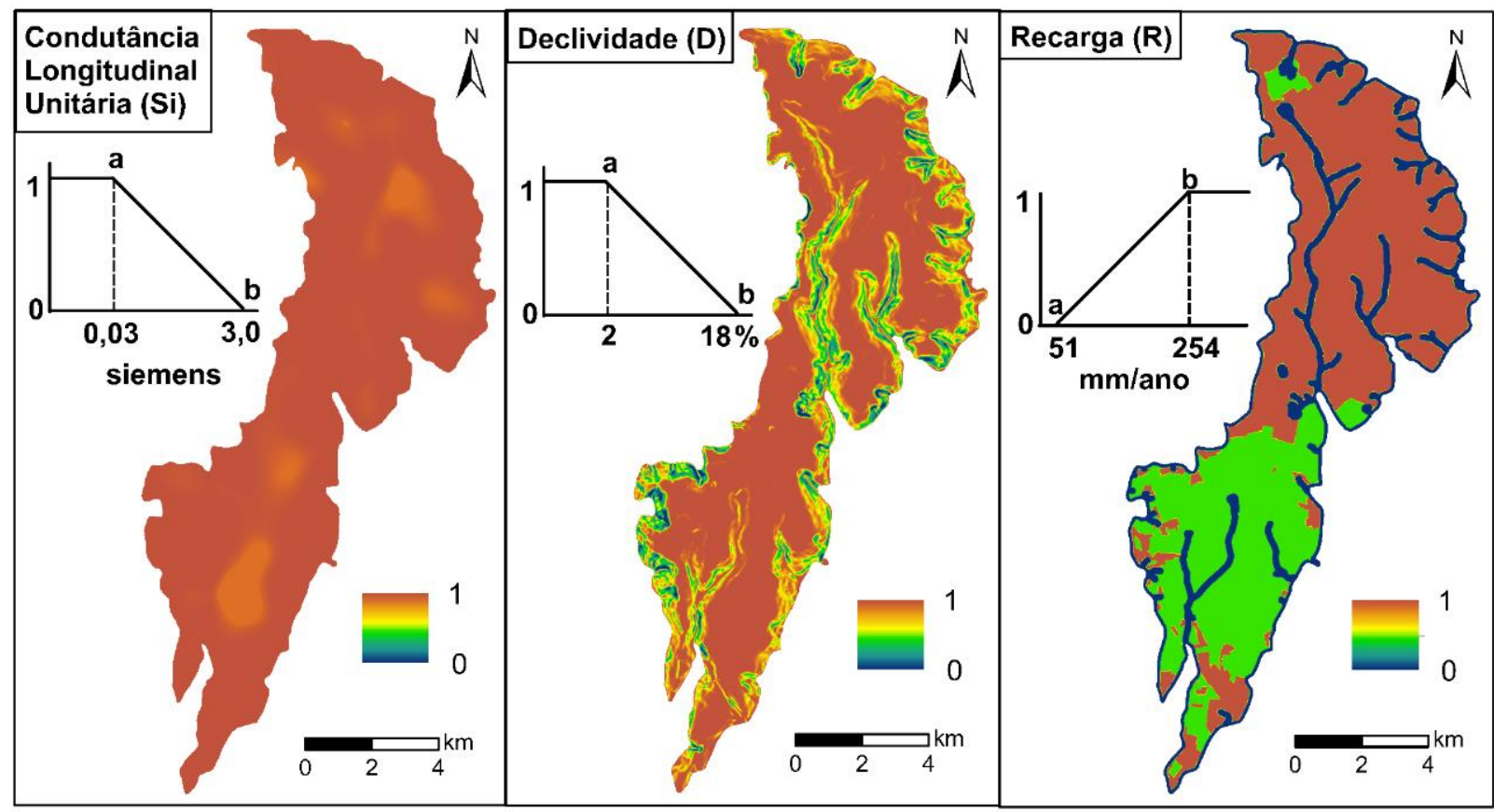

\section{Integração dos Fatores}

Figura 4. Mapas dos fatores padronizados e as funções de pertinência fuzzy.

Para gerar o mapa de vulnerabilidade natural, os fatores foram agregados por meio da Combinação Linear Ponderada (CLP) (Voogd, 1983). A partir da CLP, cada fator padronizado é multiplicado pelo seu respectivo peso e, em seguida, são somados conforme a Equação 6.

$$
\mathrm{V}=\sum \mathrm{w}_{\mathrm{i}} \cdot \mathrm{x}_{\mathrm{i}}
$$

onde: $\mathrm{V}=$ vulnerabilidade natural; $\mathrm{w}_{\mathrm{i}}=$ peso do fator $i$; $x_{i}=$ escore do fator i. Na Figura 5, esquematiza-se o processo decisório do método SDR no contexto da Avaliação Multicritério (AMC).

\section{Análise de Sensibilidade (AS)}

De acordo com Saltelli et al. (2004), a Análise de Sensibilidade (AS) explora as relações entre a saída e as entradas na aplicação de um determinado modelo de avaliação. Em outras palavras, corresponde ao estudo de como a variação na saída de um modelo (numérico ou não) pode ser distribuída, qualitativa ou quantitativamente, entre diferentes fontes de variação e como o modelo depende da informação que o alimenta. A AS é crucial para a validação e calibração de 
modelos numéricos, podendo ser utilizada para verificar a robustez do resultado, em função de pequenas mudanças nos dados de entrada (Chen et al., 2010).

Para identificar os fatores que exercem maior influência sobre o mapa de vulnerabilidade natural gerado a partir do método SDR, foi utilizada uma adaptação do método One-At-aTime (OAT), cuja proposta original é investigar as sensibilidades dos pesos unidimensionais variando a influência relativa de cada fator separadamente, enquanto o restante das entradas não é alterado (Daniel, 1958; Saltelli et al., 2000). Como o somatório dos pesos de fator deve ser igual a 1 para a aplicação na Combinação Linear Ponderada (CLP), foi necessário ajustar os demais pesos em função de cada peso alterado.

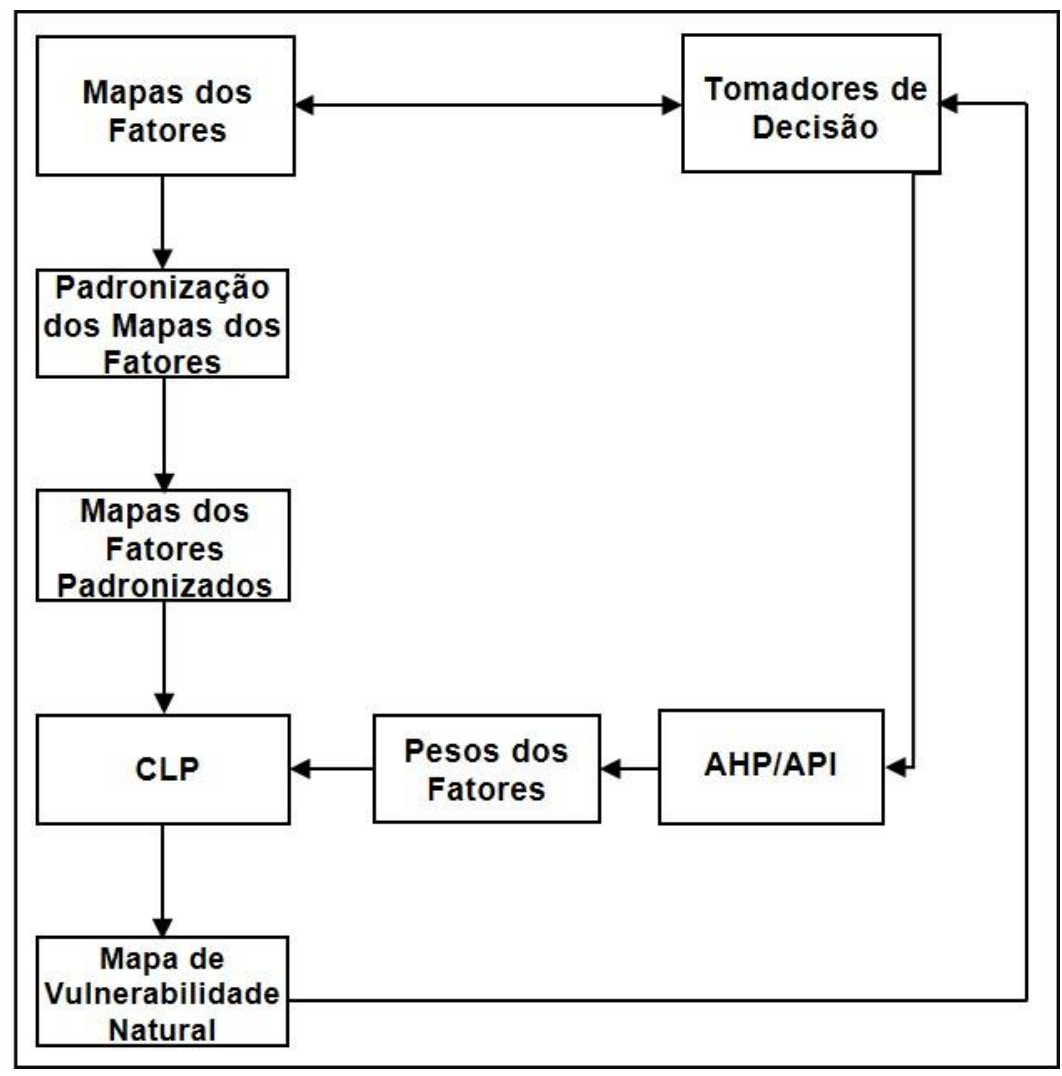

Figura 5. Processo decisório no método SDR.

A AS foi baseada na abordagem sugerida por Xu \& Zhang (2013), que representa uma estrutura de trabalho baseada na análise de sensibilidade espacialmente explícita do método OAT. Esta abordagem permite a produção de índices resumidos de sensibilidade para a área de estudo, possibilitando também a visualização espacial de áreas mais sensíveis a variações dos pesos de fator, por meio da observação de mapas de taxas de mudança local gerados a partir das simulações.

O método $O A T$ requer a configuração de dois parâmetros: 1) o intervalo de variação (iv); e 2) o tamanho do passo da alteração dos pesos (tv). Desse modo, foi atribuído um tamanho de passo de $\pm 10 \%$ e intervalo de variação de $\pm 80 \%$, ou seja: iv $=\{-80 \%,-70 \%,-60 \% \ldots+60 \%,+70 \%,+80 \%\}$.

A análise de sensibilidade foi iniciada a partir da variação do peso do fator condutância longitudinal unitária, em seguida a declividade e, por último, a recarga. Para alterar cada um dos pesos destes fatores, individualmente, foi aplicada a Equação 7:

$$
\overline{\mathrm{p}}_{\mathrm{j}}=(1+\mathrm{tv}) \cdot \mathrm{p}_{\mathrm{j}}
$$

onde: $\overline{\mathrm{p}}_{\mathrm{j}}=$ novo peso do fator $\mathrm{j}$ alterado pelo método $O A T ;$ tv = taxa de variação do peso ou tamanho do passo de alteração; $p_{j}=$ peso original do fator $\mathrm{j}$ obtido na AHP.

A Equação 8 apresenta o cálculo dos novos pesos dos demais fatores, que foram ajustados em função do peso alterado via método $O A T$. A aplicação das Equações 7 e 8 garante que os três novos pesos de fator somem sempre 1, condição necessária para a utilização da CLP.

$$
\bar{p}_{i}=p_{i} \cdot \frac{\left(1-\bar{p}_{j}\right)}{\left(1-p_{j}\right)}
$$


onde: $\overline{\mathrm{p}}_{\mathrm{i}}=$ novo peso de fator $\mathrm{i}$ ajustado em relação ao peso $\bar{p}_{j} ; p_{i}=$ peso original do fator $i$ obtido na AHP; $\overline{\mathrm{p}}_{j}=$ novo peso do fator $\mathrm{j}$ alterado pelo método $O A T ; \mathrm{p}_{\mathrm{j}}=$ peso original do fator $\mathrm{j}$ obtido na AHP.

Em seguida, foram simulados 48 mapas de vulnerabilidade natural através da CLP, a fim de efetuar a análise de sensibilidade. A Equação 9 foi usada para produzir estes mapas, a qual é apresentada a seguir:

$$
\mathrm{V}_{\mathrm{S}}=\left(\overline{\mathrm{p}}_{\mathrm{j}} \cdot \mathrm{m}_{\mathrm{j}}\right)+\sum_{\mathrm{i} \neq \mathrm{j}}^{\mathrm{n}}\left(\overline{\mathrm{p}}_{\mathrm{i}} \cdot \mathrm{m}_{\mathrm{i}}\right)
$$

onde: $\mathrm{V}_{\mathrm{S}}=$ mapa de vulnerabilidade natural simulado; $\overline{\mathrm{p}}_{\mathrm{j}}=$ novo peso do fator $\mathrm{j}$ alterado pelo método $O A T ; \mathrm{m}_{\mathrm{j}}=$ mapa padronizado do fator $\mathrm{j}$; $\overline{\mathrm{p}}_{\mathrm{i}}=$ novo peso do fator i ajustado em relação ao peso $\overline{\mathrm{p}}_{\mathrm{j}} ; \mathrm{m}_{\mathrm{i}}=$ mapa padronizado do fator $\mathrm{i} ; \mathrm{n}=$ número de fatores.

A sensibilidade das simulações foi representada por Taxas de Mudança Local (TML), que foram calculadas entre o mapa de vulnerabilidade original e aqueles resultantes do método OAT. Assim, a sensibilidade de cada pixel ou local pôde ser visualizada espacialmente em 48 mapas de taxa de mudança gerados por meio da Equação 10, a seguir apresentada:

\section{RESULTADOS E DISCUSSÃO}

\section{Pesos dos Fatores}

A partir da aplicação da AHP e agregação das opiniões dos especialistas através da API, foram obtidos os pesos de fator apresentados na Tabela 2.

Em todos os julgamentos paritários realizados, a Razão de Consistência (RC) foi menor do que 0,1 , cuja média geométrica foi de 0,034. Segundo Saaty (1980), isto indica que não houve incoerência nos julgamentos efetuados.

$$
\mathrm{TML}=\frac{\mathrm{V}_{\mathrm{S}}-\mathrm{V}_{\mathrm{O}}}{\mathrm{V}_{\mathrm{O}}} \times 100 \%
$$

onde: $\mathrm{TML}=$ mapa de taxa de mudança local (\%); $\mathrm{V}_{\mathrm{s}}=$ mapa de vulnerabilidade natural simulado; $\mathrm{V}_{\mathrm{o}}=$ mapa de vulnerabilidade natural original.

Finalmente, foram produzidos 48 indicadores numéricos de sensibilidade, considerando todas as simulações de mapas de taxa de mudança local. Para tanto, foi aplicado um método estatístico tradicional, isto é, a Média da Taxa de Mudança Absoluta (MTMA), de acordo com a Equação 11:

$$
\text { MTMA }=\sum_{\mathrm{k}=1}^{\mathrm{N}} \frac{1}{N} \times\left|\frac{\left(\mathrm{V}_{\mathrm{S}}-\mathrm{V}_{\mathrm{O}}\right)}{\mathrm{V}_{\mathrm{O}}}\right| \times 100 \%
$$

onde: MTMA = média da taxa de mudança absoluta (\%); $\mathrm{V}_{\mathrm{s}}=$ mapa de vulnerabilidade natural simulado; $\mathrm{V}_{\mathrm{o}}=$ mapa de vulnerabilidade natural original; $\mathrm{N}=$ número total de pixels.

$\mathrm{Na}$ prática, a MTMA resume em um único valor a sensibilidade expressa em todos os pixels contidos nos mapas de taxa de mudança. É importante destacar que altos valores de MTMA indicam alta sensibilidade. Para ranquear os fatores conforme a sensibilidade do método SDR quanto à alteração dos pesos, foram elaborados gráficos da MTMA em função das taxas de variação (tv) de cada peso de fator.

No contexto da AHP, todos os especialistas consideraram a condutância longitudinal unitária um fator mais importante do que a declividade e a recarga, por conter mesmo que implicitamente, dois parâmetros fundamentais à estimativa de vulnerabilidade natural das águas subterrâneas: a profundidade do N.A. e as características dos materiais da zona não saturada, que são correlacionáveis aos valores de resistividade elétrica.

Tabela 2 - Pesos de fator calculados para o método SDR.

\begin{tabular}{c|c|c|c|c}
\hline Especialista & $\begin{array}{c}\text { Condutância } \\
\text { Longitudinal } \\
\text { Unitária }\end{array}$ & Declividade & Recarga & $\begin{array}{c}\text { Razão de } \\
\text { Consistência } \\
\text { (RC) }\end{array}$ \\
\hline 1 & 0,54 & 0,11 & 0,35 & 0,045 \\
\hline 2 & 0,53 & 0,15 & 0,32 & 0,016 \\
\hline 3 & 0,59 & 0,13 & 0,28 & 0,011 \\
\hline 4 & 0,57 & 0,11 & 0,32 & 0,084 \\
\hline 5 & 0,51 & 0,20 & 0,29 & 0,040 \\
\hline 6 & 0,56 & 0,15 & 0,29 & 0,041 \\
\hline 7 & 0,50 & 0,17 & 0,33 & 0,045 \\
\hline Pesos de Fator & 0,54 & 0,14 & 0,32 & 0,034 \\
\hline
\end{tabular}


Ainda segundo o grupo consultado, mesmo que a topografia interfira no processo de infiltração, a quantidade de água que efetivamente atinge o aquífero é um fator preponderante, pois viabiliza o transporte de poluentes. $\mathrm{Na}$ realidade, a recarga deve ser compreendida como o resultado da interação entre aspectos geológicos, topográficos e climáticos. Em áreas muito planas, de clima úmido e com solos muito permeáveis, a participação da recarga pode ser ainda mais acentuada.

Por isso, quando comparado à declividade, o fator recarga foi considerado mais importante. Em outros sistemas de avaliação de vulnerabilidade, como o DRASTIC (Aller et al., 1987) e o SINTACS (Civita \& De Maio, 1997), o grau de importância relativa atribuída à recarga também é maior do aquele estabelecido para a declividade. Os índices de vulnerabilidade natural do método SDR podem ser obtidos por meio da Equação 12:

$$
\mathrm{V}_{\mathrm{SDR}}=0,54 . \mathrm{S}_{\mathrm{i}}+0,14 . \mathrm{D}+0,32 . \mathrm{R}
$$

onde: $\mathrm{V}_{\mathrm{SDR}}=$ mapa de vulnerabilidade natural do método SDR; $\mathrm{S}_{\mathrm{i}}$, D e R = mapas padronizados dos fatores condutância longitudinal unitária, declividade e recarga, respectivamente.

\section{Vulnerabilidade Natural à Contaminação - Método SDR}

De modo geral, todo o Aquífero Rio Claro foi classificado como de vulnerabilidade alta (Figura 6). Por isso, o exercício de atividades com elevado potencial de poluição deve ser planejado e gerenciado com muita cautela pelos gestores públicos, visto que a alta vulnerabilidade do aquífero impõe muitas restrições quanto ao uso e ocupação do solo. Este resultado é devido, essencialmente, às características da Formação Rio Claro, onde predominam pequenas profundidades do N.A. e materiais arenosos, muito permeáveis e que se correlacionam a altos valores de resistividade, resultando em baixos valores de condutância longitudinal unitária.

A profundidade do nível d'água subterrânea varia entre 2,0 m (região sudoeste da Formação Rio Claro) e 25,3 m (região norte). Há uma ampla variação de profundidade compreendida neste intervalo, predominando valores inferiores a 18 m (Chang \& Oliva, 2007).

A correlação entre o material predominante e sua resistividade elétrica indica que a zona saturada apresenta comportamento geoelétrico predominantemente correlacionável a sedimentos arenosos, predominando eletrofácieis com resistividade entre $250 \Omega . \mathrm{m}$ e $500 \Omega$.m (Oliva, 2006).

A condutância longitudinal unitária $\left(\mathrm{S}_{\mathrm{i}}\right)$ varia no intervalo entre 0 e $0,23 \Omega^{-1}$, sendo que os menores valores estão situados nas proximidades dos canais de drenagem e das nascentes. Os maiores valores de condutância longitudinal unitária são encontrados nos interflúvios, onde a espessura da zona não saturada é maior e principalmente na região centro-sul da Formação Rio Claro, que engloba grande parte da área urbana e o Distrito Industrial do município de Rio Claro/SP (Francisco, 2018).

A alta vulnerabilidade não deve ser atribuída apenas a características geológicas da Formação Rio Claro, mas à associação destas com aspectos geomorfológicos como a declividade, a qual interfere na taxa de recarga. $\mathrm{Na}$ área de estudo, prevalecem relevos muito planos, os quais favorecem a infiltração direta das chuvas pela zona não saturada, contribuindo para a recarga do Aquífero Rio Claro.

Em regiões onde predominam tipos de coberturas que não impermeabilizam o solo (vegetação natural, áreas agrícolas e pastagens), a recarga é igual a $438 \mathrm{~mm} / \mathrm{ano}$. Áreas com alto grau de impermeabilização, por exemplo, a porção sul do aquífero onde se localiza a área urbana do município de Rio Claro/SP, a taxa de recarga é três vezes menor, ou seja, 146 mm/ano. Nas proximidades da rede hidrográfica, nascentes e do contato com o aquitardo (Formação Corumbataí), a recarga é nula, pois estas áreas constituem zonas de descarga do aquífero (Gonçalves, 2016).

Em comparação com os resultados reportados pelo IG et al. (1997), DAEE \& LEBAC (2013) e por Zanetti et al. (2013), os quais utilizaram os métodos GOD e DRASTIC, o mapa de vulnerabilidade natural gerado pelo método SDR ofereceu o mesmo resultado, ou seja, toda a área de estudo apresentou alta vulnerabilidade natural à contaminação, o que de certo modo, valida sua aplicação.

\section{Análise de Sensibilidade (AS)}

A partir da adaptação do método $O A T$, foram simulados mapas de vulnerabilidade natural por meio da variação dos pesos de fator no intervalo compreendido entre $-80 \%$ e $+80 \%$, com uma taxa de variação dos pesos igual a $10 \%$. Entre cada 

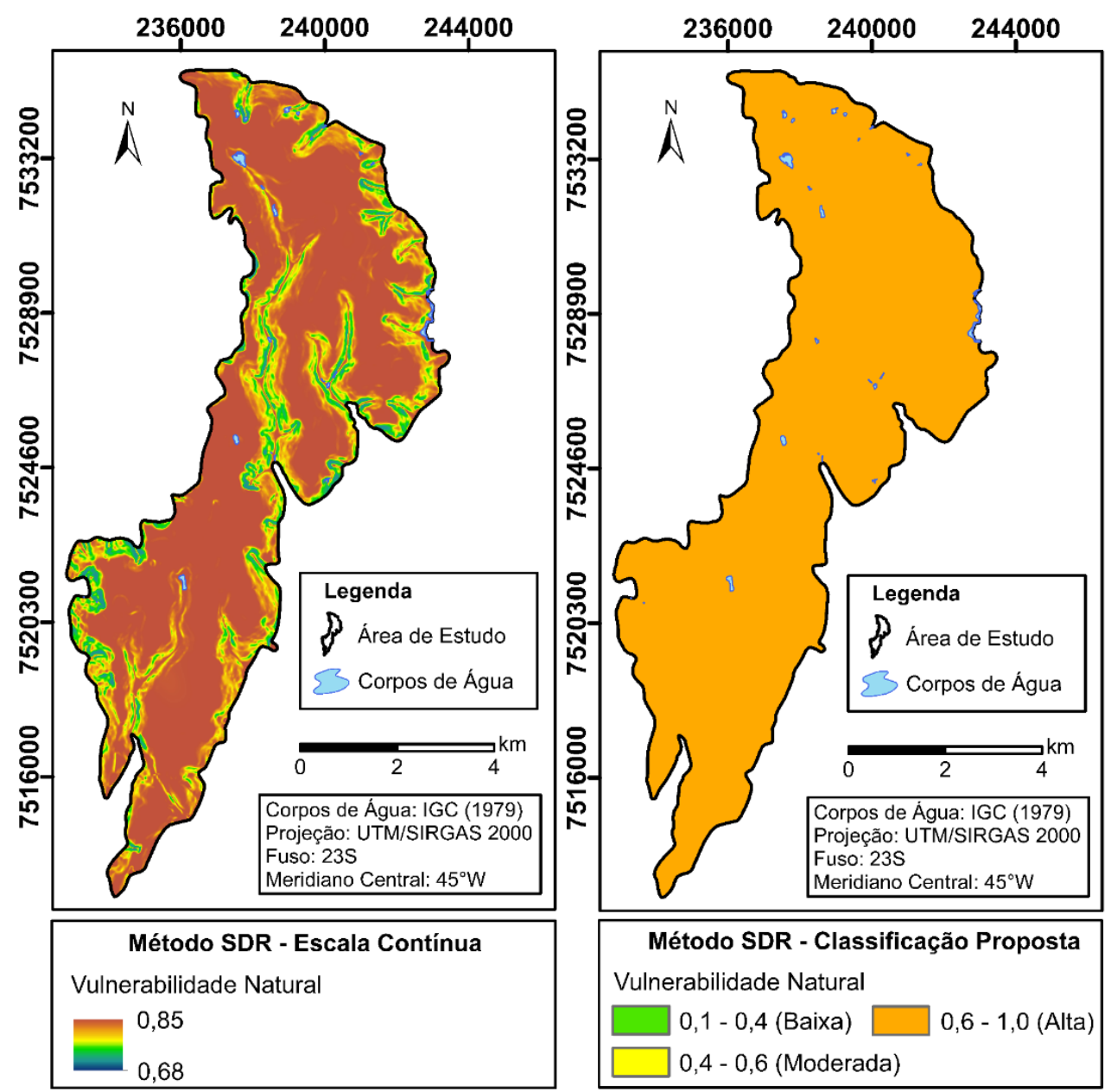

Figura 6. Vulnerabilidade natural do Aquífero Rio Claro - método SDR.

mapa de vulnerabilidade simulado e o original foram geradas as MTMA (Figura 7), que sintetizam as médias das taxas de mudança absoluta entre estes mapas, baseadas na variação dos pesos de fator.

A Figura 7 mostra o aumento linear das MTMA com o aumento das taxas de variação dos pesos, porém, com diferentes gradientes ou inclinações das retas, para cada fator avaliado. Considerando intervalos de variação positivos e negativos, para um mesmo critério, as MTMA são iguais em módulo, o que indica sensibilidades semelhantes para taxas de variação positivas e negativas.

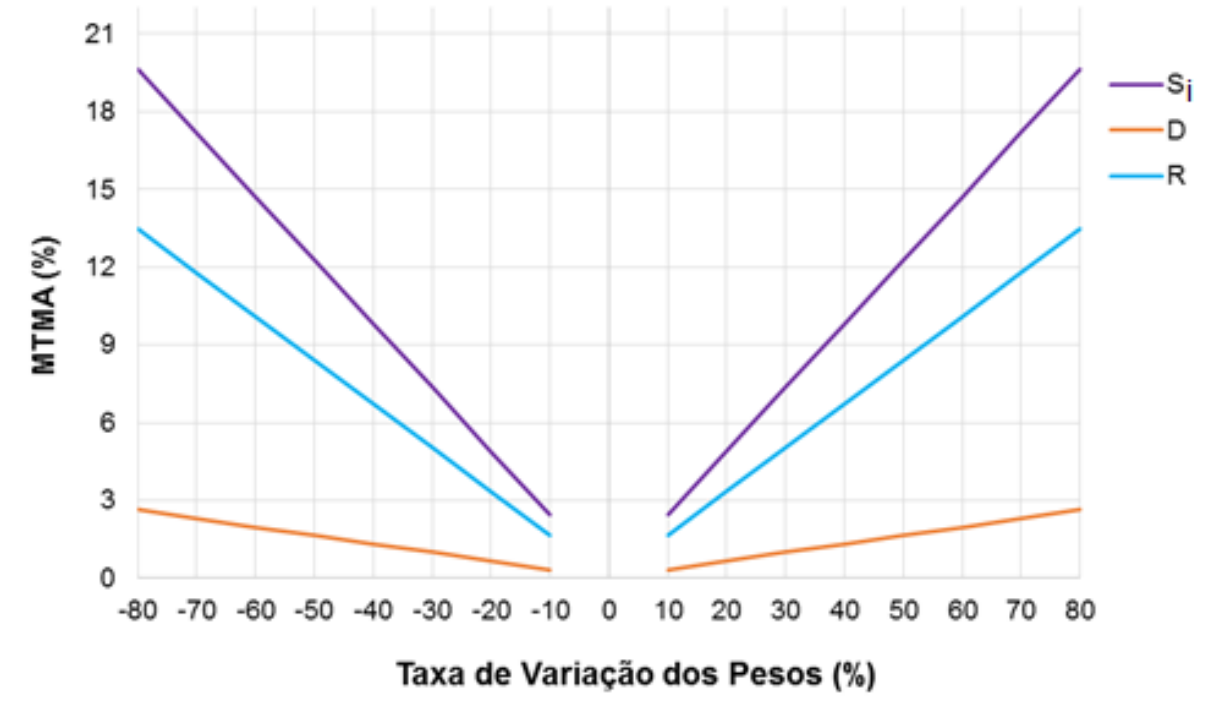

Figura 7. Média da Taxa de Mudança Absoluta (MTMA). 
Gradientes altos correspondem a maiores modificações nos escores dos mapas de vulnerabilidade gerados com a alteração dos pesos, indicando elevada sensibilidade do modelo à variação do peso. De acordo com os valores das MTMA, a ordem de sensibilidade do método SDR aos fatores é a seguinte: $\mathbf{S}_{\mathbf{i}}>\mathbf{R}>\mathbf{D}$. Este ranqueamento valida os resultados da AHP, pois seguiu a ordem decrescente dos pesos de fator. É válido salientar que este resultado pode ser diferente em outra área de estudo, pois a análise de sensibilidade depende dos pesos associados aos escores dos fatores, que variam conforme as características intrínsecas de cada local.

Em outras palavras, o fator $\mathrm{S}_{\mathrm{i}}$, ao qual foi atribuído maior peso na $\operatorname{AHP}(0,54)$, é aquele que ofereceu maior sensibilidade ao método SDR. De modo similar, o fator $\mathrm{D}$, que recebeu o menor peso $(0,14)$, representou o fator menos sensível. Tomando-se como exemplo a taxa de variação de $+80 \%$, o fator $S_{i}$ apresentou uma MTMA igual a $19,65 \%$, enquanto que a MTMA do fator D foi de apenas $2,65 \%$.

Como exemplo da visualização espacial da sensibilidade, são apresentados na Figura 8 os mapas de Taxa de Mudança Local (TML), gerados a partir da variação de $+80 \%$ dos pesos dos três fatores. É importante ressaltar que, para fins de interpretação espacial da sensibilidade, os pixels com maiores valores absolutos de TML foram classificados como mais sensíveis, desconsiderando o aumento ou diminuição da vulnerabilidade natural representado pelo sinal da TML.
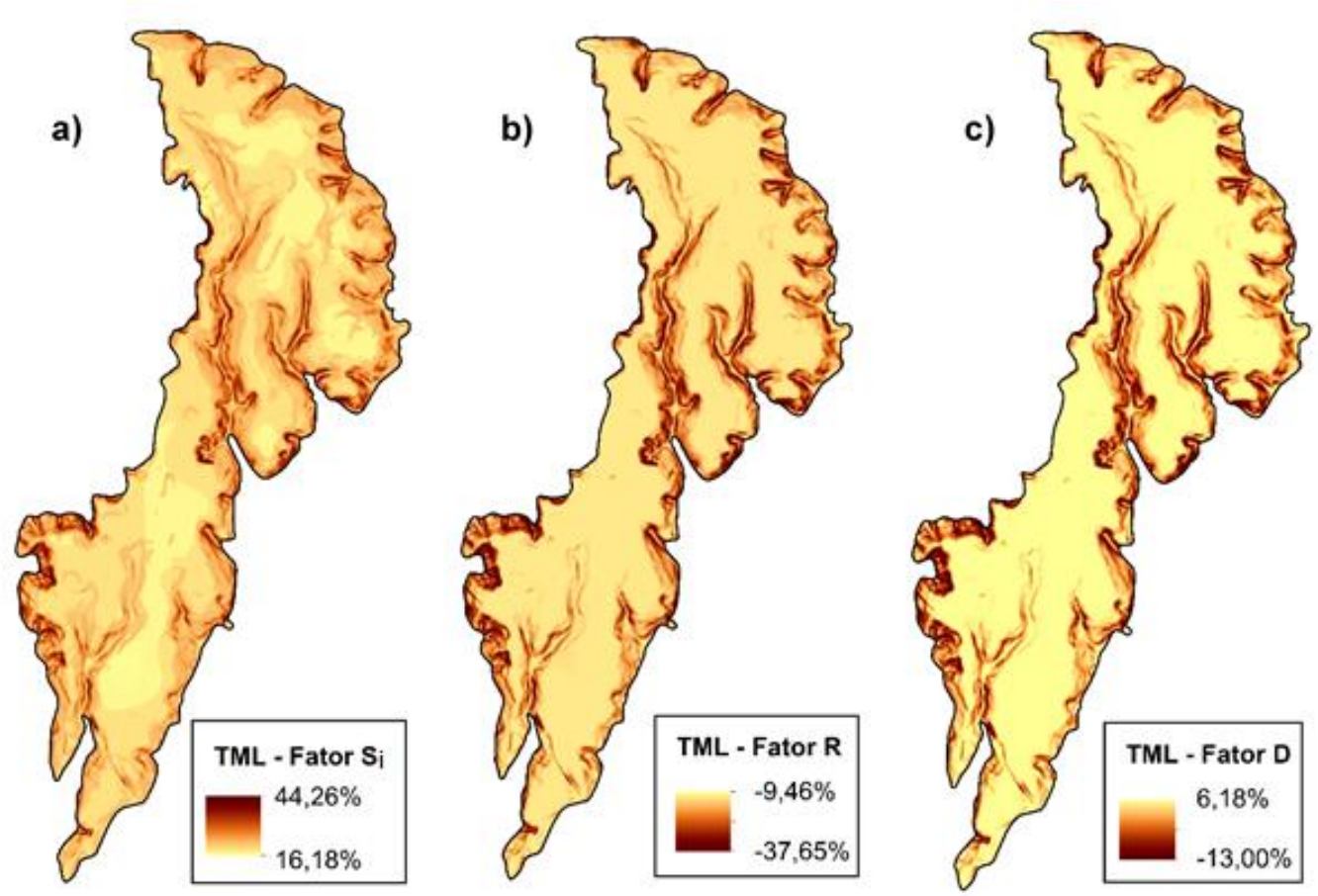

Figura 8. Mapas de Taxa de Mudança Local (TML) dos escores de vulnerabilidade natural, considerando a taxa de variação dos pesos igual a $+80 \%$.

Em comparação com os fatores $\mathrm{R}$ e $\mathrm{D}$, a variação espacial da sensibilidade do fator $S_{i}$ foi maior (Figura 8a), o que indica que a condutância longitudinal unitária, de fato, representa o critério mais sensível, pois a alteração do seu peso induziu a maiores perturbações no mapa de vulnerabilidade natural. As TML em cada pixel foram positivas, permitindo afirmar que a alteração do peso de 0,54 para 0,97 resultou em um aumento dos escores de vulnerabilidade.

Quanto ao fator R, as TML em todos os pixels foram negativas (Figura 8b), comprovando a redução dos escores de vulnerabilidade. A respeito disto, é possível concluir que, com o aumento do peso da recarga de 0,32 para 0,58 , houve uma redução significativa do peso do fator $\mathrm{S}_{\mathrm{i}}$, de 0,54 para 0,34 .

Neste caso, a vulnerabilidade foi mais afetada pelo ajuste do fator $S_{i}$ do que pelo aumento de $80 \%$ do peso do fator $\mathrm{R}$, corroborando o ranqueamento dos critérios quanto à sensibilidade.

De um modo geral, considerando todos os fatores, áreas menos sensíveis ocorrem onde os escores são altos para todos os fatores (alta vulnerabilidade), sendo pouco afetadas pela alteração de um único peso de critério. No entanto, locais com vulnerabilidade mais baixa 
são mais sensíveis, especialmente quando a variação do peso ocorre num fator com maior influência no modelo, como é o caso da condutância longitudinal unitária.

Por exemplo, considerando o mapa de TML do fator D (Figura 8c), as áreas com diminuição acentuada da vulnerabilidade, geralmente, estão localizadas onde os escores padronizados de declividade são baixos, ou seja, em relevos mais inclinados e menos vulneráveis. Por outro lado, áreas com aumento pronunciado dos índices de vulnerabilidade apresentam escores altos para o fator $\mathrm{D}$, onde predominam relevos planos e mais vulneráveis.

\section{CONCLUSÕES}

De forma genérica, foram satisfatórios os resultados da aplicação experimental do método SDR, considerando as respostas esperadas conforme os aspectos litológicos, hidrogeológicos, topográficos e climáticos da Formação Rio Claro.

Os parâmetros selecionados sintetizaram com bastante clareza a influência de um conjunto de fatores que, direta ou indiretamente, contribuem para a estimativa da vulnerabilidade das águas subterrâneas.

Desse modo, é possível avaliar a vulnerabilidade intrínseca de aquíferos livres granulares, a partir da ponderação e integração de apenas três fatores, algo muito interessante considerando o cenário de escassez de dados disponíveis em diversas regiões do Brasil.
A respeito disto, a condutância longitudinal unitária desponta como um parâmetro bastante promissor no âmbito da avaliação de vulnerabilidade natural, visto que reflete, ainda que de modo sintético e indireto, as características da zona não saturada. Outra vantagem representada pelo emprego da condutância longitudinal unitária são os custos reduzidos e menor tempo para sua obtenção.

Finalmente, o método SDR representa uma nova alternativa àqueles considerados tradicionais, pois sua aplicação ofereceu um resultado robusto. Ademais, apresenta vantagens sob o ponto de vista da praticidade na utilização e do número reduzido de parâmetros requeridos, podendo desempenhar um papel importante na proteção de aquíferos livres granulares.

\section{AGRADECIMENTOS}

Os autores gostariam de agradecer ao Departamento de Geologia Aplicada, do Instituto de Geociências e Ciências Exatas - IGCE/UNESP pelo suporte técnico e à Coordenação de Aperfeiçoamento de Pessoal de Nível Superior - CAPES, pelo auxílio financeiro na forma de concessão de bolsa de estudo.

\section{REFERÊNCIAS}

AKPAN, A.E.; EBONG, E.D.; EMEKA, C.N. Exploratory assessment of groundwater vulnerability to pollution in Abi, southeastern Nigeria, using geophysical and geological techniques. Environmental Monitoring and Assessment, v. 187, n. 4, p. $1-18,2015$.

ALLER, L.; BENNETT, T.; LEHR, J.H.; PETTY, R.J.; HACKETT, G. Drastic: a standardized system for evaluating groundwater pollution potential hydrogeologic setting. Environmental Protection Agency (EPA), Washington (DC), Report 600/2-87-035, 1987.

ARCHIE, G.E. The electrical resistivity $\log$ as an aid in determining some reservoir characteristics. Petroleum Transactions of AIME, v. 146, p. 54-62, 1942.

BRAGA, A.C.O. Geofísica aplicada: métodos geoelétricos em hidrogeologia. 1. ed. São Paulo: Oficina de Textos, 160, p. 2016

BRAGA, A.C.O. \& FRANCISCO, R.F. Natural vulnerability assessment to contamination of unconfined aquifers by Longitudinal Conductance - (S) method. Journal of Geography and Geology, p. 68-79, 2014.

CEAPLA - CENTRO DE ANÁLISE E PLANEJAMENTO AMBIENTAL. Malha digital da área urbana do município de Rio Claro - pontos cotados, curvas de nível e rede hidrográfica, na escala 1:10.000, 2011.

CHANG, H.K. \& NOGUEIRA, G.E.H. Simulação numérica de fluxo de águas subterrâneas do Aquífero Rio Claro, porção nordeste do município de Rio Claro, SP. Águas Subterrâneas, v. 29, n. 2, p. 175-190, 2015.

CHANG, H.K. \& OLIVA, A. Mapeamento do lençol freático no município de Rio Claro (SP) empregando a técnica da sondagem elétrica vertical. Geociências, v. 16, n. 1, p. 27-34, 2007.

CHANG, H.K.; CAETANO CHANG, M.R.; OLIVA, A. Determinação da condutividade hidráulica da Formação Rio Claro: análise comparativa através de análise granulométrica e ensaios com permeâmetro Guelph e testes de Slug. Águas Subterrâneas, v. 19, n. 2, p. 1-17, 2005.

CHEN, Y.; KHAN, S.; PAYDAR, Z. To retire or expand? A fuzzy GIS-based spatial multi-criteria evaluation framework for irrigated agriculture. Irrigation and Drainage, v. 59, n. 2, p. 178-188, 2010.

CIVITA, M.; \& DE MAIO, M. SINTACS: un sistema parametrico per la valutazione e la cartografia della vulnerabilità degli acquiferi all'inquinamento. Metodologia e automazione. Bologna: Pitagora, 191 p., 1997.

DAEE-DEPARTAMENTO DE ÁGUAS E ENERGIA ELÉTRICA, LABORATÓRIO DE ESTUDO DE BACIAS LEBAC/Unesp. Águas subterrâneas no Estado de São Paulo: diretrizes de utilização e proteção. São Paulo, 44 p., 2013

DAEE-DEPARTAMENTO DE ÁGUAS E ENERGIA ELÉTRICA. Estudo de águas subterrâneas - região administrativa 5 (Campinas). São Paulo, 1981. 
DANIEL, C. On varying one factor at a time. Biometrics, v. 14, n. 3, p. 430-431, 1958.

EASTMAN, J.R. IDRISI Taiga: guide to GIS and image processing. Worcester: Clark University, Clark Labs, 2011.

FORMAN, E. \& PENIWATI, K. Aggregating individual judgements and priorities with the Analytic Hierarchy Process. European Journal of Operational Research, v.108, p. 165169, 1998.

FOSTER, S.S.D. \& HIRATA, R. Avaliação do risco de poluição das águas subterrâneas: uma metodologia baseada em dados existentes. Organização Mundial de Saúde, Organização Pan-americana de Saúde, Centro Pan-americano de Engenharia Sanitária e Ciências Ambientais. Lima, 78 p., 1988.

FRANCISCO, R. F. Contribuição metodológica à estimativa da vulnerabilidade natural e perigo de contaminação de aquíferos livres granulares. Rio Claro, 2018. Tese (Doutorado em Geociências e Meio Ambiente), Instituto de Geociências e Ciências Exatas, Universidade Estadual Paulista.

GEMAIL, KH.S.; EL-ALFY, M.; GHONEIM, M.F.; ELSHISHTAWY, A.M.; ABD ELBARY, M.H. Comparison of DRASTIC and DC resistivity modeling for assessing aquifer vulnerability in the central Nile Delta, Egypt. Environmental Earth Sciences, v. 76, n. 350, 2017.

GONÇALVES, R.D. Modelagem numérica e avaliação hidrogeológica do Aquífero Rio Claro. Rio Claro, 2016. Dissertação (Mestrado em Geociências e Meio Ambiente), Instituto de Geociências e Ciências Exatas - Universidade Estadual Paulista.

HENRIET, J.P. Direct applications of the Dar Zarrouk parameters in ground water surveys. Geophysical Prospecting, n. 24, p. 344-353, 1975.

IGC-INSTITUTO GEOGRÁFICO E CARTOGRÁFICO DO ESTADO DE SÃO PAULO-Cartas topográficas do Estado de São Paulo. São Paulo: Instituto Geográfico e Cartográfico, 1979. Articulações: Ajapi (SF-23-Y-A-I-4-NE-B), Granja Ipê (SF-23-YA-I-4-NE-D), Fazenda São José (SF-23-Y-A-II-3NO-C), Bairro Cachoeirinha (SF-23-Y-A-I-4-NE-F), Córrego Água Boa (SF-23-Y-A-II-3-NO-E). Escala 1:10.000.

IG-INSTITUTO GEOLÓGICO. Formações geológicas de superfície do Estado de São Paulo. São Paulo: Instituto Geológico, 1986. Articulações: SF-23-M-II-3 (Araras), SF-23M-I-4 (Rio Claro). Escala 1:50.000.

IG-INSTITUTO GEOLÓGICO. Mapeamento da vulnerabilidade e risco de poluição das águas subterrâneas no Estado de São Paulo. IG/CETESB/DAEE. (Coord) HIRATA, R.C.A.; BASTOS, C.R.A.; ROCHA, G.A., São Paulo. 1997.

MAILLET, R. The fundamental equations of electrical prospecting. Geophysics, v. 12, n. 4, p. 529-556, 1947.

MELO, S.M. A Formação Rio Claro e depósitos associados: sedimentação Neocenozoica na Depressão Periférica Paulista. São Paulo, 1995. 144 p. Tese (Doutorado em Geociências), Instituto de Geociências, Universidade de São Paulo.

MOSURO, G.O.; ADEKOYA, F.; ATOBI, O.; BAYEWU, O.O.; LANIYAN, T.A.; OKUBENA, M.; OLORUNTOLA, M.O.; OMOSANYA, K.O.; POPOOLA, E. Assessment of groundwater vulnerability to leachate infiltration using electrical resistivity method. Applied Water Science, p. 1-13, 2016.

NDATUWONG, L.G. \& YADAV, G.S. Application of geoelectrical data to evaluate groundwater potential zone and assessment of overburden protective capacity in part of Sonebhadra district, Uttar Pradesh. Environmental Earth Sciences, v. 73, n. 7, p. 3655-3664, 2015.
NIAZ, A.; KHAN, M.R.; MUSTAFA, S.; HAMEED, F. Determination of aquifer properties and vulnerability mapping by using geoelectrical investigation of parts of Sub-Himalayas, Bhimber, Azad Jammu and Kashmir, Pakistan. Quarterly Journal of Engineering Geology and Hydrogeology, v. 49, p. 36-46, 2016.

OLIVA, A. Estudo hidrofaciológio do aquífero Rio Claro no município de Rio Claro - SP. Rio Claro. 2006. 244 p. Tese (Doutorado em Geociências e Meio Ambiente), Instituto de Geociências e Ciências Exatas-Universidade Estadual Paulista.

OLIVA, A. Estudo hidrogeológico da Formação Rio Claro no município de Rio Claro - SP. Rio Claro. 2002. 71 p. Dissertação (Mestrado em Geociências e Meio Ambiente), Instituto de Geociências e Ciências Exatas-Universidade Estadual Paulista.

ORELLANA, E. Prospección geoelectrica em corriente continua. Madrid: Paraninfo, Biblioteca Tecnica Philips, 523, p. 1972.

SAATY, T.L. The Analytic Hierarchy Process. New York: McGraw-Hill, 287 p., 1980.

SAATY, T.L. Decision making with the analytic hierarchy process. International Journal of Services Sciences, v. 1, n. 1, p. 83-98, 2008.

SALTELLI, A.; TARANTOLA, S.; CAMPOLONGO, F. Sensitivity analysis as an ingredient of modelling. Statistical Science, v. 15, n. 4, p. 377-395, 2000.

SALTELLI, A.; TARANTOLA, S.; CAMPOLONGO, F.; RATTO, M. Sensitivity analysis in practice: a guide to assessing scientific models. 1. ed. West Sussex: John Wiley \& Sons, 2004.

SENDRÒS, A.; DIAZ, Y.; HIMI, M.; TAPIAS, J.C.; RIVERO, L.; FONT, X.; CASAS, A. An evaluation of aquifer vulnerability in two nitrate sensitive areas of Catalonia (NE Spain) based on electrical resistivity methods. Environmental Earth Sciences, v. 71, n. 1, p. 77-84, 2014.

VAN STEMPVOORT, D. \& EWERT, L.; WASSENAAR, L. AVI: a method for groundwater protection mapping in the prairie provinces of Canada, 23 p., 1992.

VOOGD, H. Multicriteria evaluation for urban and regional planning. London: Pion, 370 p., 1983.

XU, E. \& ZHANG, H. Spatially-explicit sensitivity analysis for land suitability evaluation. Applied Geography, v. 45, p. 1-9, 2013.

ZAINE, J.E. Geologia da Formação Rio Claro na Folha Rio Claro - SP. Rio Claro, 1994. 90 p. Dissertação (Mestrado em Geociências), Instituto de Geociências e Ciências ExatasUniversidade Estadual Paulista.

ZANETTI, N.; BRAGA, A.C.O.; SANTOS, F.A.M. Estimativa da vulnerabilidade natural do aquífero livre no município de Rio Claro/SP. Revista Brasileira de Geologia de Engenharia e Ambiental, v. 3, n. 1, p. 9-20, 2013.

Submetido em 14 de setembro de 2018 Aceito em 24 de outubro de 2018 